\title{
A Preliminary Study on Pop Music Teaching in Colleges and Universities Shi Pu
}

\author{
School of music, Hubei Normal University, Wuhan, 435002, China
}

\author{
Keywords: Colleges and universities; Pop music; Teaching
}

\begin{abstract}
Pop music teaching is significant for music learners to cultivate good moral character and personality. As a very important part of higher education, the status of music teaching has been increasing in recent years. In the music teaching system in colleges and universities, we need to pay attention to make full use of pop music. So, in the environment where pop music becomes more and more popular among college students, how to carry out pop music teaching is what we must give full attention to. This paper analyzes the enormous influence of pop music on contemporary college students and the current situation of pop music teaching in higher education, and puts forward some countermeasures to improve the pop music teaching in colleges and universities.

In recent years, the continuous progress of society leads people to pursue fine music art. Music is an influential comprehensive art, which is very effective on enhancing the capacity of modern aesthetic and cultivating sentiments of modern people. Given the depth of pop music into of people's daily life and work, college students naturally are affected profoundly. However, the current pop music teaching in colleges and universities is not enough, which makes public to wonder how to introduce pop music teaching course in college. Therefore, to get better results from college music education, we need to promote pop music teaching in music teaching at colleges and universities.
\end{abstract}

\section{Pop Music's Great Influence on Contemporary College Students}

The popularity of pop music among contemporary young college students has exceeded people's imagination, which verifies that some content of pop music is fully in line with the aesthetic taste of college students and in full compliance with the practical needs of college students. For example, tone of pop music is easy to sing, which is able to be enjoyed by young people; the lyrics are very simple and relatively easy to remember, therefore, college students can easily understand them. So the form of pop music is able to be accepted by college students. Meanwhile, pop music creators are as young as college students, which can make young students to form a strong resonance to some extent and enrich young students' spiritual and cultural life. But what can't be ignored is that pop music is very commercial, which is a serious disconnection to pure art. While young students don't have enough ability to distinguish this situation, so they would be affected easily. And it is not conducive to college students' comprehensive development. Negative factors such as grievance and sadness revealed from pop music can easily transfer to college students and make them depressed.

\section{Analysis of Current Pop Music Teaching in Colleges and Universities}

Pop music teaching in colleges and universities has made some progresses in recent years, but there are failings. The specific situation is as follows:

First, in the context of the development of higher education, colleges and universities continue to increase enrollment, creating developing space for many new subjects, which forms a sufficient external condition for the development of pop music education. This is the external factor. No one can stop the tide of pop music all over the world which has considerable influence on the development of China's pop music. Internal dynamics of pop music itself has become a growing internal factor for its increasing development, which together promote the development of music education in Chinese colleges and universities. Although China's popular music education has achieved good development, gained some good experience and achievements, there are still a considerable number of issues need to be addressed further. In general, music education in Chinese 
universities takes Western classical music as its main content, which is the criterion for judgment whether in the value judgment, or in the aesthetic standards. China's current system of music education is from Western classical music, which leaves far-reaching influence on music education in higher education. Currently, popular music programs have been established in a considerable part of the universities in our country, but because most of the popular music content is usually from the teaching system of Western music, and most of the teachers in pop music have received orthodox Western music education who, whether it is in the thinking mode or in the knowledge system, still holds the original model, which lead popular music teaching philosophy to depend on Western classical music education model greatly. So the discipline construction and teaching philosophy of pop music lack of adequate and strong independence

Second, in view of the settings and content of pop music teaching in higher education, whether name (profession) of department in colleges and universities, or name of professional research direction, etc., academic circle didn't achieve a consensus. Vague of definition of pop music teaching related names naturally affected the properly implementation of teaching position. For example, the unclear confirmation of border, content and extension among pop music, secular music and modern music determines the multiplicity of teaching position in higher education, and leaves considerable difficulties on the discipline construction. We not only need to get rid of the ambiguous definition of the name of pop music, but also should effectively address the vague teaching content on pop music. Of course, it is common that teachers carry out teaching using traditional teaching model, while training objectives and teaching programs are basically followed the Western classical music teaching model.

\section{Countermeasures to Improve Pop Music Teaching in Colleges and Universities}

(1) Updating Concept of Education Effectively

A considerable number of music teachers in colleges and universities feel that in order to be able to sing good songs, one must first go to learn Bel Canto. I think there is a problem in this view. It should be said, various ways of singing indeed have a lot of similarities physiologically, one can learn from each other. But in terms of aesthetics it is completely different. It is actually a misunderstanding of concept. The negativity of this misunderstanding is considerable, only to form a good attitude first, one can be possible to recognize the singing of pop music. Bel Canto teaching in the traditional sense is not superior to the singing of pop music and individual teaching. Pop music teaching workers must be committed to finding and exploring vocalization, singing techniques and aesthetic rules which can be adapted to pop music singing. They can also learn from the Bel Canto to find commonalities between Bel Canto and pop music singing. For example, we can learn from the scientific, standardized respiratory training of Bel Canto to enhance the support on the breath for the pop music; we can learn the clearly audibility of folk singing to strengthen articulation and enunciation when singing pop music, etc. . There is another view that if the pop singing pursues method too much, it would lack of taste which it deserves and it wouldn't be fashionable. I think this idea is one-sided. Music teachers still need to use the scientific method to train college students singing skills. Only with good skills, learners can play the most ideal sound effects. However, we can't use the inherent model to control learners singing style. Teaching must be based on the characteristics of pop music such as diversity and fashion. Teachers should make clear the importance of scientific singing skills, and firmly grasp the pulse of the development of the times, using a variety of ways to understand the developing trend of pop music, to update teaching ideas and teaching methods continuously. Thus, teachers are able to make the singing of pop music get continuous sublimation and development, which can meet the aesthetic requirements of the present age.

(2) Adding Theory Courses of Pop Music

With the constantly evolving of time, modern society demands more and more music talents of pop music. Some professional music colleges and universities have pioneered specialized profession of pop music, and some ordinary colleges and universities, to adapt to the needs of development of situation, gradually form and pay attention to the professional settings of pop music. 
For example, one can find that in the curriculum structure of colleges and universities, the main courses of pop music profession are Chinese music history, Western music history, appreciation of masterpieces and foreign and folk music which have quite a distance from the pop music. At the time of setting pop music professional courses, ordinary colleges and universities can learn from the rich teaching experience of many domestic professional musical institutions, introducing related theory courses such as foreign pop music appreciation, the history of Western pop music and movie music. In this way, pop music majors can strengthen the important theoretical basis and improve their music quality.

(3) Enhancing Practice of Pop Music Courses

In order to meet the requirements of the development of the age and social progress, there have been more and more ordinary colleges and universities putting emphasis on the new teaching content of pop music, which is one of the important progresses in China's pop music education. Talented pop music professionals in colleges and universities are not to popularize knowledge of pop music to the whole society. Colleges and universities should train highly qualified personnel in the field of pop music and music performers in the future, which requires learners, not only should have a very excellent pop music singing or professional ability of theoretical research, but also need to have solid theoretical foundation and creative capability. So, in the process of setting pop music courses, we should focus on making full use of pop music's pertinence to the maximum. For example, the piano courses in ordinary music colleges or music department. It is not enough for pop music professional learners, so it is better to set the courses of unified piano accompaniment or accompaniment courses as popular keyboard playing and singing courses. Eligible colleges and universities can set up very practical courses such as guitar, band performances and recordings so that learners can learn more clearly and more comprehensively of pop music knowledge and skills. In this way, it is possible to achieve the purpose of highly specialized training of professionals, in an effort to cultivate high level and high quality pop music talents.

(4) Strengthening the Infectivity of Pop Music Teaching

Pop music teaching in colleges and universities should be like a hundred flowers in bloom while not to stick to one pattern. This requires selecting the most appropriate teaching methods, and on the basis of general music textbooks, to incorporate pop music into classroom selectively, which not only would not affect the sound teaching, but also can enrich the content of teaching and consolidate music-related knowledge effectively. Such an action can cultivate college students' innovation and promote students' strong interest in pop music learning. As more and more outstanding pop songs entering into music classrooms, a majority of music teachers gradually accept them. They should carry out some positive and bold practices to make the education value of the pop music to full display. When pop music enters into teaching directly, teachers need to meticulous screen by emotion and style, humanistic connotations and understandings in their creations, to ensure the provision of good feelings and correct values for college students. Through practice, one can clearly recognize that outstanding pop songs have a subtle effect, so that good pop songs can enter into music classroom and become a bridge of learning. For example, in the teaching process of Erhu Solo : " The Moon Reflected in Two Springs ", teachers can choose "Chanting of Two Springs" written by Zeng Jing as an introduction, which is dignified and contains strong affectionate. The lyrics fully display A Bin's sorrow and anger, deep sympathy and heartfelt praise, which naturally incorporate A Bin into the song. In addition, when students are appreciating the violin concerto "Butterfly Lovers", teachers can independently choose the singing version of "Butterfly Lovers" of the band Black Ducks as song melody accompaniment. The melody of two versions of "Butterfly Lovers" is melodious, sweet and light and the singing likes a beautiful dizzying picture. As the song sounded, the melody imported by learners is very beautiful: the music is high-pitched and boosting for one moment, and then becomes lingering crooning for another moment, which is very effective to enhance the unique infectivity of pop music teaching in higher education in our country. 


\section{Conclusion}

In summary, in practical music teaching in colleges and universities, the impact of pop music on contemporary students is considerably great. The reason why a majority of learners like pop music proves its own merits. In view of this, we should view pop music dialectically. We should not deny it completely. We need to put the factors which can cultivate learner's sentiment into music teaching in higher education. So that we can make music teaching in colleges and universities better fit the actual needs of learners, thereby improving learners' musical quality and promoting the enhancement of a new generation of college students.

\section{References}

[1]Wang Qingjin. "On the Role of Pop Music in Music Education in Colleges and Universities" [J].. China Innovation of Science and Education Journal, 2010(25).

[2]Sang Xiao. "Discussion of Music Education Reform Based on Popular Music Background" [J]. Chinese Educational Technology Equipment, 2012(6).

[3]Jang Wen. "Discussion of Music Education Reform Based on Popular Music Background" [J]. Chinese extramural Education, 2012(12).

[4]Yang Liu. "Inquiry of Feasibility and Teaching Suggestions of Pop Music in College Public Music Lessons" [J]. Music, 2014(3).

[5]Zhong Jianhong. "Application of Pop Music in Music Education in Colleges and Universities" [J]. Music Time, 2014(9). 